I found that if I could classify eye in a language under examination, it gave me sun and many other words, and it led me to much valuable work, but I was often thrown out for reasons I did not then know. Empirically I found eye was a constant, and $I$ knew it was a round, because in many languages east and west sun is the day eye or day's eye; moon is the night eye, and eye the bead eye. In the North American languages and in the Malay, for instance, there was the evidence of a common law of psychological philology, which led me to greater results. My knowledge became modified to the extent that sun was not day eye, but day round. Until Mr. Wallace's article appeared, I still regarded eye as the pivot on which the "round" words and characters turned, although I knew that mouth was the prototype of moon, mother, woman, egg, \&c., and of objects and ideas having a periodicity or a month. Having a false pivot, I was never able to bring the facts into a right connection, although coming very near. The Chinese modifications of the ancient character show that mouth and ring constitute the primary character, and thereby indicate the primary word.

The researches of Col. Garrick Mallery, U.S.A., and my own, in the paper unpublished, show the connection of sign language and characters, and I have determined a relation between sign language, character, and words, as in the sign or character i। for son, offspring, \&c. The characters in many cases appear as ancient as the signs, and may have preceded speech language. How words were connected with ideas and their representatives by signs was the problem. The new explanations of $\mathrm{Mr}$ : Wallace in your paper, or the old observations of others, in giving explanations from natural cries and sounds, \&c., are not always exact, and do not account for the fact that the sounds are in relation with the sign language. Thus the words for eye and 2 are the same, and the words for ear and 3 , and so forth.

In the brief remarks now made I endeavour to steer clear of many things which would require a long explanation, and to bring my observations to bear on Mr. Wallace's article. On speech language being constituted, the application of a labial to mouth gave a large series, and so of the dentals, \&c. As the numerals are in relation to each object of the universe in primitive symbology, so they were supplied. Indeed nouns, adjectives, pronouns, verbs, numerals, particles, were supplied from a common fount. There are languages constituted of a few differentiated words, which can be traced throughout.

In connection with Mr. Wallace's remarks is to be taken what he says afterwards of the action of the lips. In the sign languages and the characters the lower organs supply a large number of ideas regarded as phallic. Such are $11,+., O$, \&c. These ideas are not capable of direct connection with sounds; they came however into connection by the acknowledged correspondence of the parts in symbology and mythology. Thus the labial sounds became the representatives of actions or ideas illustrated by the corresponding lower organs, as in go and come.

Taking Mr. Wallace's terms and applying them, we therefore get the connection established between the sign languages and the speech languages, and we can see the psychological grounds on which they continued in work ing together, and why the speech languages have not everywhere always exterminated their ancestors. For this, and for the whole state of affairs, Mr. Wallace furnishes me with an explanation.

His naked statement is the best, that for mouth a labial was used. In the sign languages, and we fird this in the prehistoric languages and their equivalents, several signs are used for one idea, and several ideas for one sign. When a labial was applied for the mouth, it was indifferent what labial. If one nsed a $b$, another would use $m$. This is one cause of the variety we find in the prehistoric primary languages, for there never was what philologists are fond of, one primitive language.

Many will object to Mr. Wallace, that mouth is not always represented by a labial, and in the common course hold that the negative evidence overcomes the affirmative. In many instances mouth is a dental, because the idea includes the teeth, which are dental. Again tongue is not always a dental, but a sibilant, so far as it is connected with snake. It is the whole knowledge of the facts which will better enable us to complete our progress and to overcome difficulties. For myself 1 have derived particular advantage from Mr. Wallace, in being enabled to understand my own work.

32, St. George's Square, S.W.

\section{Comets and Balloons}

THE notion that the tails of comets are produced by an emis sion of the nucleus prevails at present among astronomers. I have just stated in a small pamphlet, 8 vo, 32 pages, the reason why I presume to entertain another opinion on this subject. The details of my last aërial trip of July 2 show that by using an electric light night ascents at a reasonable distance from the sea may be considered as relatively without danger. The appearance of Schäberle's comet seems to me to afford a proper occasion for testing the emission theory, and I will try to explain my idea as shortly as possible.

It is pretty certain that any comet will lose something of its brilliancy in consequence of passage to the perihelion, consequently, cateris paribus, it must be found with a diminished luminous power in the second part of its track. The consequence is that to test this theory the same comet should be observed in a similar position, as close as possible, in the first and in the second parts of its track.

By ascending with a balloon in the northern hemisphere to inspect Schäberle's comet on a moonless night, and estimating its luminous power in a clear sky at several determined heights, a great step will be made in reaching this desirable end.

It would be for the astronomers of the southern balf of the world to ascend under similar conditions, and to make corresponding observations. If no visible diminution is proved to have taken place, much will have been accomplished in the determination of the true nature of this mysterious object.

The same observations could, it is true, be prosecuted without the help of aërostation, but not with the same amount of certainty, as much doubt remains as to the true luminosity of a celestial body when it is not inspected in a really perfectly clear sky, which can always be procured with a balloon-it is true not without incurring some personal risk, certainly not out of proportion, at all events, to the results to be expected.

\section{W, DE Fonvielle.}

\section{Animal Instinct}

I AM exposed to some annoyance from a clever old donkey, who, being turned out on to the green in front of my house, constantly lets himself into my garden to graze on my lawn. This he effects by pushing his nose between the rails of an iron gate, and then pressing down the latch of the gate. Expulsion, with ever so striking an appeal to his feelings, avails only a short time for his exclusion, unless the gate is locked.

Little Park, Enfield, August I9

W. B. Kesteven

\section{ITALIAN DEEP-SEA EXPLORATION IN THE MEDITERRANEAN}

A FTER my communication of the 4th inst. from Asinara I feel sure that many readers of NATURE will be interester' to know something more of our doings; so I take the opportunity of our short stay here to send a very brief account of our doings since leaving Asinara.

The presence of a deep-sea fauna in the Mediterranean which I announced in my last is fully confirmed, and even though most of the species dredged are as yet undetermined, I can venture to say that the character of this fauna is "Atlantic," and, I may add, "Oceanic." My first bit of news was the capture of a Willemosia identical, or very nearly allied, to $W$. leptodactyla; since then some ten or twelve specimens of that most interesting and characteristic Crustacean have been secured off the west, south, and east coasts of Sardinia, in depths varying from 950 to 2145 metres. All our deep hauls have brought up some living animals, usually Annelids and deep-red shrimps of at least three species; the greatest depth we have trawled in is 3115 metres; the greatest we have found sounding is 3630 metres in the eastern basin between Sardinia and Naples.

On the roth inst., off the west coast of Sardinia we dredged two specimens of a Macrurid fish, which I take to be a Malacocethalus, from depths of 2805 and 2908 metres. South of the Gulf of Cagliari we got a new-to me-and exceedingly remarkable Macrurid, with what 
look like the so-called supplementary eyes along the belly and tail, the rare Macrurus sclerorhyncus, Hoplostethus Mediterraneus, and Haloporphyrus lepidion, from depths of $508,656,860$, and I 25 metres. We have at least two species of Terebratula from depths varying from 600 to I 200 metres. Several most interesting Crustaceans besides those mentioned, and even a non-swimming Brachyurous Decapod, from II25 metres! But what is still more interesting is the capture of several specimens of a Hyalonema, very probably $H$. Lusitanica, but without any spiral twist in its long spiculæ; we got them off the south and east coasts of Sardinia, in depths from 1600 to 623 metres; we have, besides, several other forms of Sponges, all siliceous, and several of a curious agaric-like form. We have a Brisinga from depths of 2145 to 2300 metres, but very few other Echinoderms; I do not yet give up the hope of seeing a Pentacrinus before our cruise is ended. We have, as I mentioned, various Annelids and Gephyreans, and some fine species of Madreporia of the deep-sea forms.

We have an interesting set of serial thermometric observations, which show that there is a slight difference in the bottom temperature between the basins east and west of Sardinia, the latter being slightly colder. Negretti and Zambra's new deep-sea thermometers have answered admirably, suspended in the peculiar frame devised by Capt. Magnaghi.

Naples, August 20

\section{ON THE VELOCITY OF LIGHT}

$\mathrm{THE}$ result announced by Young and Forbes (Roy. Soc. Proc., May I7, I881) that blue light travels in vacuo about 1.8 per cent. faster than red light, raises an interesting question as to what it is that is really determined by observations of this character. If the crest of an ordinary water wave were observed to travel at the rate of a foot per second, we should feel no hesitation in asserting that this was the velocity of the wave; and I suppose that in the ordinary language of undulationists the velocity of light means in the same way the velocity with which an individual wave travels. It is evident however that in the case of light, or even of sound, we have no means of identifying a particular wave so as to determine its rate of progress. What we really do in most cases is to impress some peculiarity, it may be of intensity, or of wave-length, or of polarisation, upon a part of an otherwise continuous train of waves, and determine the velocity at which this peculiarity travels. Thus in the experiments of Fizeau and Cornu, as well as in those of Young and Forbes, the light is rendered intermittent by the action of a toothed wheel; and the result is the velocity of the group of waves, and not necessarily the velocity of an individual wave. In a paper on Progressive Waves (Proc. Math. Soc. vol. ix.), reprinted as an appendix to vol. ii. of my book on the "Theory of Sound," I have investigated the general relation between the group-velocity $U$ and the wave-velocity $V$. It appears that if $k$ be inversely proportional to the wave-length,

$$
U=\frac{d(k V)}{d k}
$$

and is identical with $V$ only when $V$ is independent of $k$, as has hitherto been supposed to be the case for light in vacuum. If however, as Young and Forbes believe, $V$ varies with $k$, then $U$ and $V$ are different. The truth is however that these experiments tell us nothing in the first instance about the value of $V$. They relate to $U$; and if $V$ is to be deduced from them it must be by the aid of the above-given relation.

When we come to examine more closely the form of this relation, we see that a complete knowledge of $V$ (as a function $k$ ) leads to a complete knowledge of $U$, but that a complete knowledge of $U$-all that experiments of this kind can ever give us-does not determine $V$, without the aid of some auxiliary assumption. The usual assumption is that $V$ is independent of $k$, in which case $U$ is also independent of $k$. If we have reason to conclude from observation that $U$ is not independent of $k$, this assumption is disproved; but we can make no progress in determining $V$ until we have introduced some other.

It is not easy to see how the missing link is to be supplied; but in order to have an idea of the probable magnitude of the difference in question I have assumed the ordinary dispersion formula $V=A+B k^{2}$ to be applicable. Taking the ratio of wave-lengths of the orange-red and green-blue lights employed as $6: 5$, I find that for red light $V=U(1-0273)$, so that the velocity of the wave would be nearly 3 per cent. less than that given by Young and Forbes as the result of the experiment.

Under these circumstances it becomes a matter of interest to examine the bearing of other evidence on the question of the velocity of light. Independently of the method of the toothed wheel, the velocity of light has been determined by Foucault and Michelson using the revolving mirror. It is not very obvious at first sight whether the value thus arrived at is the group-velocity or the wave-velocity, but on examination it will be found 0 be the former. The successive wave-fronts of the light after the first reflection are not parallel, with the consequence that (unless $V$ be constant) an individual wave-front rotates in the air between the two reflections.

The evidence of the terrestrial methods relating exclusively to $U$, we turn to consider the astronomical methods. Of these there are two, depending respectively upon aberration and upon the eclipses of Jupiter's satellites. The latter evidently gives $U$. The former does not depend upon observing the propagation of a peculiarity impressed upon a train of waves, and therefore bas no relation to $U$. If we accept the usual theory of aberration as satisfactory, the result of a comparison between the coefficient found by observation and the solar parallax is $V$-the wave-velocity.

The question now arises whether the velocity found from aberration agrees with the results of the other methods. A comparison of the two astronomical determinations should give the ratio $U: V$, independently of the solar parallax. The following data are taken from Mr. Gill's "Determination of the Solar Parallax from observations of Mars made at the Island of Ascension in I877."

The time $k$, required by light to travel a mean radius of the earth's orbit, has been determined by two astronomers from the eclipses of Jupiter's satellites. Delambre found, from observations made in the last century, $k=493^{\circ} 2 \mathrm{~s}$., but recently Glasenapp has obtained from modern observations the considerably higher value, $k=500.8 \mathrm{~s} . \pm \mathrm{I} \cdot 02$. With regard to the constant of aberration, Bradley's value is $20^{\prime \prime} \cdot 25$, and Struve's value is $20^{\prime \prime} 445$. Mr. Gill calculates as the mean of the best modern determinations (nine in number), $2 \mathrm{O}^{\prime \prime} \cdot 496$.

If we combine Glasenapp's value of $k$ with Michelson's value of the velocity of light, we get for the solar parallax 8.76 . Struve's constant of aberration in conjunction with the same value of the velocity of light gives $8 " .8 \mathrm{r}$. From these statements it follows that if we regard the solar parallax as known, we get almost the same velocity of light from the eclipses of Jupiter's satellites as from aberration, although the first result relates to the group velocity, and the second to the wave velocity. If instead of Struve's value of the constant of aberration we take the mean above spoken of, we get for the solar parallax $8^{\prime \prime} \cdot 78$, allowing still less room for a difference between $U$ and $V$.

Again, we may obtain a comparison without the aid of the eclipses of Jupiter's satellites by introducing, as otherwise known, the value of the solar parallax. Mr. Gill's 